\title{
Periorbital Ecchymosis (Racoon Eyes): A Case of a Primary Systemic Amyloidosis D Demir ${ }^{1}$, FT Demir ${ }^{1}$, IK Altunay ${ }^{1}$, H Erdogan $^{2}$, O Yalcın ${ }^{3}$
}

\begin{abstract}
Amyloidosis is a group disease which progresses with extracellular accumulation of fibrillary protein in beta conformation structure. It is categorized as localized amyloidosis when storage is limited to one organ (i.e. on skin) or systemic (generalized) amyloidosis when it occurs with several organ involvement. In this article, a primary systemic amyloidosis case diagnosed with skin lesions is presented with the purpose of reminding primary systemic amyloidosis in differential diagnosis of periorbital ecchymosis and reviewing the findings of primary systemic amyloidosis which is a rarely seen disease in dermatology practice.
\end{abstract}

Keywords: Amyloidosis, primary systemic amyloidosis, racoon eyes

From: ${ }^{1}$ Department of Dermatology, Sisli Hamidiye Etfal Training and Research Hospital, Istanbul, Turkey, ${ }^{2}$ Department of Anesthesia and Reanimation, Sisli Hamidiye Etfal Training and Research Hospital, Istanbul, Turkey, ${ }^{3}$ Department of Pathology, Sisli Hamidiye Etfal Training and Research Hospital, Istanbul, Turkey.

Correspondence: Dr FT Demir, Department of Dermatology (Specialist), Sisli Hamidiye Etfal Training and Research Hospital, Sisli, Istanbul, 34371, Turkey. Email: filizsvet@yahoo.com 


\section{INTRODUCTION}

Amyloidosis is a disease group which indicates abnormal extracellular amyloid and fibrillary proteinous material accumulation in tissues (1). While localized amyloidosis involves macular, papular and nodular subtypes, systemic amyloidosis is divided into three as primary (AL amyloidosis) and secondary (AA type amyloidosis) systemic amyloidosis and familial amyloidosis according to the accumulated amyloid protein type (2). In this article, we describe dermatological findings of a patient diagnosed with primary systemic amyloidosis that is a rarely seen in dermatology practice.

\section{CASE REPORT}

A 52-year-old female patient was transferred from intensive care unit to our clinic due to purpuric eruption around her eyes and neck. In her history, it was found out that she had had complaints of numbness in her hands and feet for 3 years, she was interned in Internal Diseases Unit for increased weight loss, difficulty in breathing and abdominal swelling and she was transferred to intensive care unit due to cardiac arrest in her monitoring. In her physical examination, her overall situation was bad and she was unconscious. In auscultation, decrease in aspiration sounds, crepitant rales in lung basels, matity in percussion, intraabdominal tension, peripheral neuropathy and oedema which leaves $2+$ godet in bilateral pretibial area were detected. In her dermatologic examination, yellowish brown pigmentation on both periorbital areas and purpuric red purpura and ecchymoses settled on the pigmentation; purpuric red petechia, purpura and ecchymoses on neck and breast V; eroded lesions on neck lateral which are partly corroded and a few erythematous tense bullous lesions on left femoral area extensor face were observed (Figure 1-3). In oral mucosa evaluation, macroglossia drew attention. In laboratory examinations of the patient, increase in kidney 
function tests (Urea: 119.3, Creatinine: 1.70), and low anaemia (Hb: $9.7 \mathrm{~g} / \mathrm{dl}$ ), CK-MB: 11.36 $\mathrm{ng} / \mathrm{ml}$ and C3c $(55 \mathrm{mg} / \mathrm{dl})$ were detected. Other laboratory examinations; ANA, anti-ds DNA, anti-cardiolipin antibody, lupus anticoagulant, SS-A, SS-B, anti Jo1 antibody, Rheumatoid factor, tumour marker and infectious agents (EBV VCA Ig M/ Ig G, toxoplasma, Brucella, HIV) were negative. In her chest radiography pleural effusion was detected and in her abdominal tomography intra-abdominal liquid and thickening in rectum were detected and in her echocardiography increase in right and left ventricle wall thickness, left ventricle disfunction, ejection fraction (EF) 50\% and pericardial effusion on left ventricle posterior wall were detected. Acid culture sent with paracentesis was sterile. In histopathologic examination of the punch biopsy taken from lesions; orthokeratosis on surface, flattening on epidermis, hyalinised amorphous substance accumulation in papillary dermis, perivascular interstitial lymphocytic infiltration and erythrocyte extravasation were present. Hyalinised amorphous substance which is stained with Congo red was evaluated as immunoglobulin light chains (AL type amyloidosis) (Figure 4). The patient, who has common organ involvement such as lung, heart, intestine, bone marrow, kidney and skin, was diagnosed with primary systemic amyloidosis with these findings. The patient who had restrictive cardiomyopathies died due to ventricular fibrillation while her examinations were in progress.

\section{DísCUSSION}

Primary systemic amyloidosis is characterized with AL amyloid fibrin accumulation which consists of monoclonal immunoglobulin light chains. It is frequently related to plasma cell dyscrasia and multiple myeloma is developed in $15 \%$ of the patients (2). In the study of Saba et al., 21 patients out of 39 who are diagnosed with systemic amyloidosis were evaluated as primary systemic amyloidosis and multiple myeloma was reported in $43 \%$ of them (3). In an 
autopsy study carried out in Germany with 43 systemic amyloidosis patients, it was detected that $23 \%$ of the cases were primary systemic amyloidosis and there were $50 \%$ myeloma (4).

Clinical findings might occur with numerous organ involvement such as renal, cardiac, neuronal and gastrointestinal system, liver and spleen. Skin involvement may be seen in $40 \%$ of the patients (2). Skin findings might be the indicator of systemic involvement as well as being the first finding of the disease. Petechial, purpura, ecchymosis, translucent nodule, xanthamatous plaques, subcutaneous nodules, bullous lesions, alopecia, macroglossia, scleroderma appearance and nail dystrophies might be observed secondary to the amyloid accumulation on the skin (5). Capillary fragility which occurs due to amyloid accumulation on blood vessel walls causes petechial and purpura. Purpura might occur on its own or due to small traumas and light stimulation (6). It is frequently presented on eyelids, neck, armpits and anogenital area. Periorbital purpura and ecchymosis are characteristically referred to as racoon eyes in the literature and it reminds amyloidosis in diagnosis. Papule and plaques frequently settle on intertriginous areas such as face, eyelids, lips, tongue, buccal mucosa, behind ears and neck, axilla, inguinal and anogenital area. They are shining, flat surfaced, yellow or skin coloured, translucent or flat and asymptomatic (7). Bullous skin lesions may also be seen. Bullous lesions occur due to accumulation of amyloid deposits on the skin and stimulated with minor traumas. They may be intra-epidermal or supra-epidermal $(8,9) .$. In our patient, there were tense bulla which extend linearly in right hypochondriac area.

Clinically it is difficult to distinguish primary, systemic or familial amyloidosis. For that reason, diagnosis is made by indicating the amyloid deposits accumulated on the tissue and it is distinguished by typology of the amyloid proteins immunohistochemically (10). Skin biopsies, rectal mucosa biopsies or abdominal subcutaneous fat aspiration biopsies can be made. Amyloid deposits are seen on dermis, subcutaneous ties and blood vessel walls. 
Prognosis of primary systemic amyloidosis is bad. The cause of death is mostly cardiac or renal failures. Cytotoxic agents such as Melfalan and Prednizolon are used in treatment (1).

As a conclusion, with this case report it is aimed to remind primary systemic amyloidosis in the differential diagnosis in patients with petechial, purpura and ecchymosis located on especially face, neck, axilla and anogenital area. 


\section{REFERENCES}

1. Lachmann HJ, Hawkins PN. Amyloidosis and the skin. In: Wolff K, Goldsmith LA, Kat SI, Gilchrest BA, Paller AS, Leffell DJ, editors. Fitzpatrick Dermatology in General Medicine. Newyork: McGraw Hill;2008.p. 1256-1265.

2. Sarkany RP, Breathnach SM, Morris AA, Weismann K, Flynn PD. Metabolic and nutritional disorders. In: Burns T, Breathnach S, Cox N, Griffiths C, editors. Rook's Textbook of Dermatology.8th ed. Oxford: Wiley-Blackwell; 2010. pp. 59.1-103.

3. Saba M, Tohme A, Abadjian G, Haddad F, Ghayad E. Multisystemic amyloidosis. Clinical study of patients in Lebanon. Presse Med 2005; 34: 640-6.

4. Strege RJ, Saeger W, Linke RP. Diagnosis and immünohistochemical classification of systemic amyloidoses. Report of 43 cases in an unselected autopsy series. Virchows Arch 1998; 433: 19-27.

5. Bayer- Garner IB, Smoller BR: The spectrum of cutaneous disease in multiple myeloma. J Am Acad Dermatol 2003; 48: 497-507.

6. Bayer-Garnerl IB, Smoller BR: AL amyloidosis is not present as an incidental finding in cutaneous biopsies of patients with multiple myeloma. Clin Exp Dermatol. 2002; 27: $240-2$.

7. Piette WW: Myeloma, paraproteinemias and the skin.Medical Clinics of North America 1986;70: 55-171.

8. Robert C, Aractingi S, Prost C, Verola O, Blanchet-Bradon C, Blanc F, et al. Bullous amyloidosis, report of 3 cases and review of the literature. Medicine. 1993; 72: 38.

9. Johnson TM, Rapini RP, Hebert AA, Lowe L, Verani R, Evanoff G. Bullous amyloidosis. Cutis. 1989; 43: 346-52.

10. Gertz MA. The classification and typing of amyloid deposits. Am J Clin Pathol 2004; 121: 787-89. 


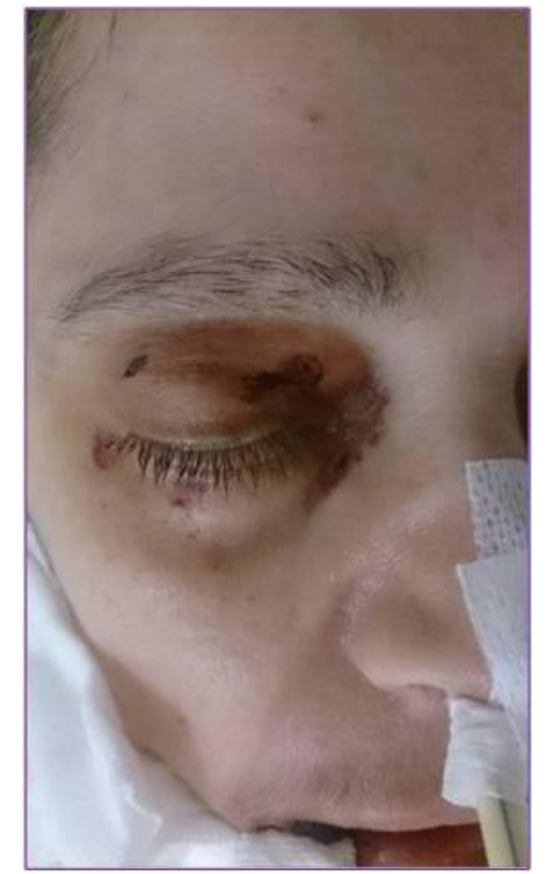

Fig 1: Purpuric and ecchymotic lesions scattered on periorbital area. (Raccoon's sign).

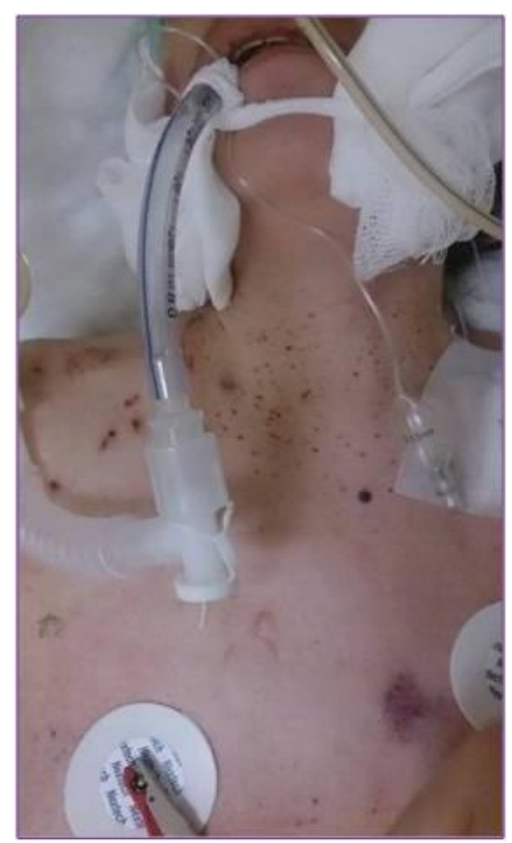

Fig 2: Petechia and purpuras on neck and chest. 


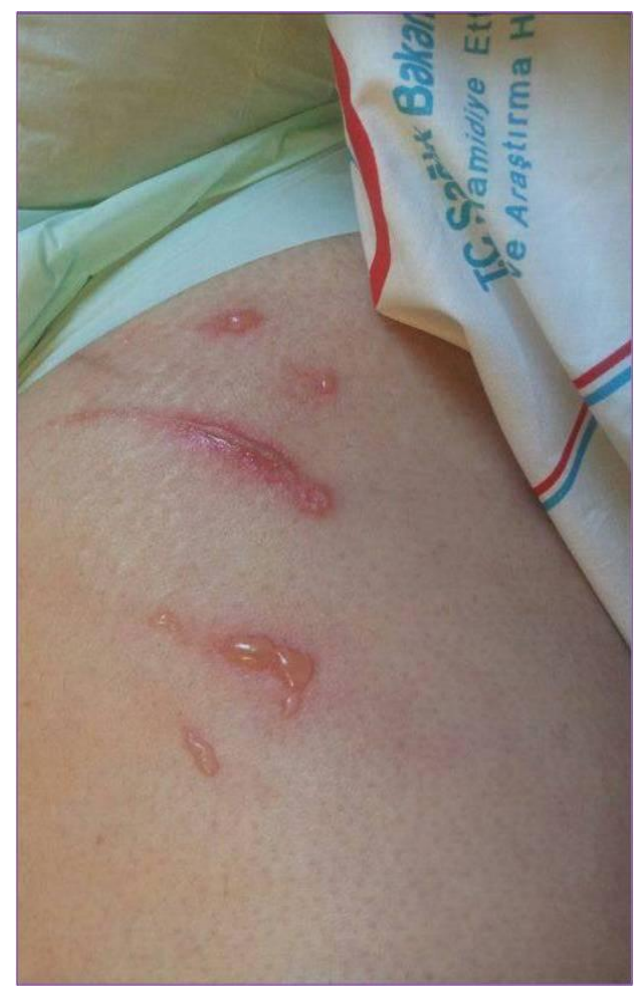

Fig 3: Tense bullae on hypochondriac area



Fig 4: Pink amyloid deposit with Crystal violet (X400). 